\title{
Wireless Sensor Network with GSM Modem for Healthcare Monitoring System
}

\author{
Mr. Sunil L. Rahane ${ }^{1}$, Prof. Ramesh S. Pawase ${ }^{2}$ \\ Department of E \& TC, Amrutvahini College of Engineering, Sangamner, India ${ }^{1,2}$
}

\begin{abstract}
This paper presents monitoring system to monitor the physiological parameters such as Blood Pressure (BP), ECG, Body Temperature and Saturation of Oxygen in blood. The paper presents the system Architecture for smart Healthcare using Wireless Sensor Network (WSN) with GSM Module and PIC18F4520 Microcontroller. In this system ECG can be monitor by using Clamp Sensor \& Oxygen saturation in blood can be monitor by using Pulse Oximeter. The applications of Healthcare are considered as promising fields for monitoring the patient's health using WSNs. The main focus of current WSN healthcare research is on patient reliable communication. A new technology in healthcare applications without considering security makes patient privacy morally. Moreover, the health data of an individual are is very sensitive. Therefore, security \& privacy is a first requirement of healthcare applications, if the patient has any disease. This paper discusses the monitoring and analysis of health issues in healthcare application using WSNs.
\end{abstract}

Keywords: Blood pressure, Energy consumption, patient privacy issues, Hospital healthcare, Wireless sensor network, wireless body area network, Healthcare applications.

\section{INTRODUCTION}

This system carries the promise of drastically improving and expanding the quality of care across a wide variety of settings and the population's different segments. Present system prototypes have demonstrated the potential of WSNs to enable early detection of clinical deterioration through real-time patient monitoring in hospitals [1], [4], enhance first responders' capability to provide emergency care in large disasters through automatic electronic instrument [2], [6], improve the life quality through smart environments [8], and enable large-scale field studies of human behavior and human diseases [5], [7].use of patient data can cause life-threatening risks to the patient, or make the patient's private matters available anywhere [3]. For example, a patient's body sensors transmit his/her body data to a nurse/caregiver.

This system use a GSM modem which is more secured to transmit patients data from one end to another end overall the world. In this system we use separate modem to each observer to monitor the data. The patient's data transmit only to the specific observer whose mobile number may be registered in the system. So there is security of patient's data, because no one cannot access the data without registered.

\section{WIRELESS SENSOR NETWORK SYSTEM}

Fig 1 shows the Block Diagram of healthcare monitoring system which consist of two different nodes with sensing parameter such as ECG, BP \& heart rate monitor, temperature, SPO2 sensor.

In this system there are different types of components $\&$ instruments used for different operation. First one different type of sensors like Thermistor is used to measure the temperature of body. Clamp sensor is used to ECG monitoring. To monitor oxygen saturation in Human blood SPO2 Sensor is used.

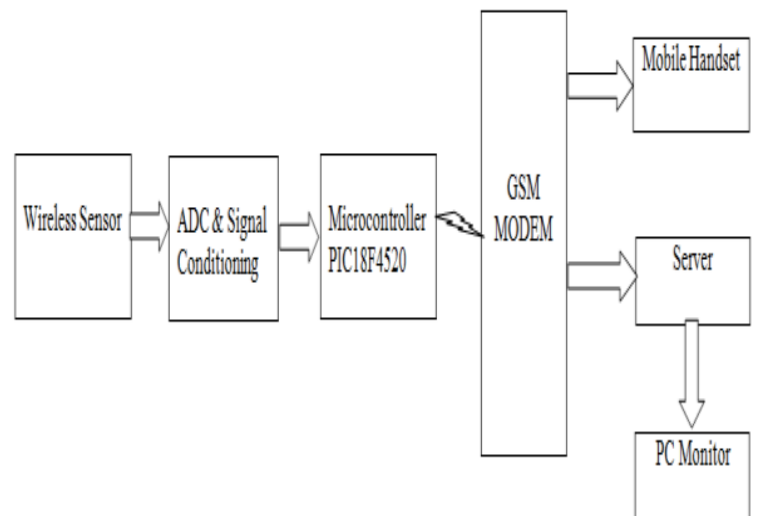

Fig 1: Block Diagram of Healthcare Monitoring System using Wireless Network System with GSM.

A. Wireless sensor network

a. Clamp type ECG Sensor

Clamp type ECG sensor is used to monitor appearance of waves, duration of waves, segments and intervals, amplitude of waves, rhythm of heart cycles and plot or process ECG signals. Clamp type sensor is used to monitor the ECG Signal Two thumbs hold on the board and you start getting output in analog form as well as in pulse form. Optocoupler are used to get clean ECG signal \& isolate ECG signal from sensor.

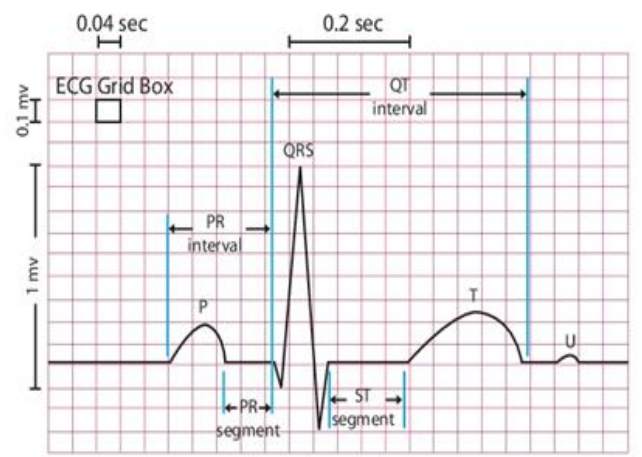

Fig 2: Healthy Person's ECG Recording 


\section{b. Temperature sensor}

To measure temperature changes in human body thermistor is used as temperature sensor. Thermistor is thermally sensitive resistors whose prime function is to produce a large, predictable and precise change in electrical resistance when subjected to a corresponding change in body temperature. (NTC) Negative Temperature Coefficient thermistors exhibit a decrease in electrical resistance when subjected to an increase in body temperature and Positive Temperature Coefficient (PTC) thermistors exhibit an increase in electrical resistance when subjected to an increase in body temperature.

\section{c. SPO2 Sensor}

$\mathrm{SpO} 2$ stands for Peripheral capillary oxygen saturation. It is basically the oxygen saturation level Sensor. The concentration of oxygen in the blood is referred by Oxygen saturation. 95 to100 percent is a Normal blood oxygen levels. Your blood oxygen level is considered low between 90 and 95 percent, but it is not necessarily indicative of a health issue. It is considered low resulting in hypoxemia when the level is below 90 percent. Sleep apnea, asthma crisis, and pulmonary infection are the causes of hypoxemia. SPO2 sensor are used to monitor Pulse Ox meter, Heart Rate Meter. The Heart Beat signal is obtained by LED and LDR combination. Blood flow though hands interrupts the Light reaching the LDR and this signal is converted into digital by ADC which then read by PIC18F4520 microcontroller. To assist increase in oxygen levels in blood Oxygen therapy is used.

\section{d. BP sensor}

Blood pressure (BP) is the pressure exerted by circulating blood upon the walls of blood vessels. Blood pressure usually refers to the arterial pressure in the systemic circulation. The blood pressure is measured at a person's upper arm. Blood pressure is usually expressed in terms of the systolic (maximum) pressure over diastolic (minimum) pressure and is measured in millimeters of mercury $(\mathrm{mm} \mathrm{Hg})$. It is the vital signs along with rate of respiratory, heartbeat, saturation of oxygen, and temperature of body. Normal resting blood pressure in an adult is approximately $120 / 80 \mathrm{~mm} \mathrm{Hg}$. To measure the blood pressure which is pressure on wall of arteries when heart contract and relax BP sensor are used.

\section{B. ADC \& Signal conditioning}

Amplifier \& filter are used as signal conditioning to remove the noise added in signal which is come from the sensors. The strength of signal is very small in strength so that there is need to signal conditioning block. After then these signal is converted into digital form by high precision analog to digital converter which has minimum 8 channels which is simultaneous. High precisions are required because all signals from patient body area very small strength thus. An analogto-digital converter (ADC) is a device that converts a continuous physical quantity (usually voltage) to a digital number that represents the quantity's amplitude.

\section{PIC18F4520 Microcontroller}

PIC18F4520 Microcontroller is used for processing the data which is come from analog to digital converter. The amplified \& conditioned signal comes from various sensors is fed to different input ports of the microcontroller. The Blood Pressure (BP), ECG, heart rate and temperature can be read \& stored in the RAM of microcontroller. It is then converted and stored in the memory as two 8-bit unsigned integers. The microcontroller constructs the SMS messages and packs the data samples after completion of signals acquisition. Then communicates with the mobile phone using at-commands on its GSM modem port to send the messages. The graph of ECG is plotted on PC.

\section{GSM Modem}

For the healthcare monitoring system SIM900 is a complete Quad-band GSM/GPRS solution. It is a SMT module. The SIM900 delivers GSM/GPRS 850/900/1800/1900MHz performance for voice, SMS, Data, and Fax in a small form factor and with low power consumption. All the space requirements in your M2M application a tiny configuration of $24 \mathrm{~mm}$ x $24 \mathrm{~mm}$ x $3 \mathrm{~mm}$, SIM900 can fit, especially for slim \& compact demand of design.

\section{E. Server}

As a web server the back-end server is programmed which delivers a web page when requested by a web browser. The data collected by sensors and the software of the system administration, data processing and analyzing, are stored on the server. Administrator can manage the whole system by accessing the web page on server. The monitored person can inquire his health status on web server through mesh router. Back-end users, such as doctors, health care advisors or relatives of patients can also inquire the health care monitoring data on the web page.

\section{F.PC}

Patients and caretaker interface with the network using PCs. For data management, querying, object location, memory aids, and configuration, depending on health monitoring for patient the PCs are used. There should be minimum interactions are supported with the on body sensors and control. These health monitoring may provide memory for history of patient, alerts and emergency communication channel.

\section{RESULT}

Figure 3 shows the observation of ECG of Patient.

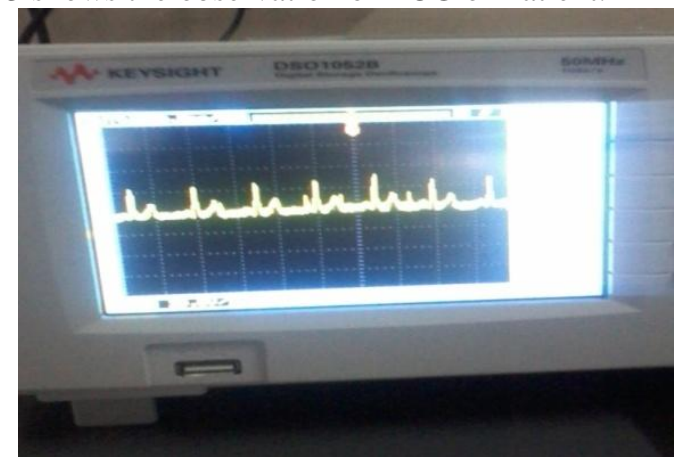

Fig 3: Patient's ECG Observe on DSO 
Figure 4 shows the observation of oxygen saturation in Human blood.

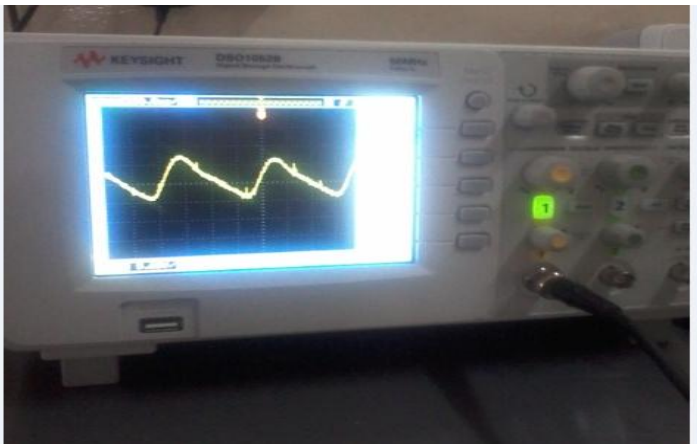

Fig 4: observation of oxygen saturation in Human blood.

\section{CONCLUSION}

The security is very important in monitoring of healthcare which may provide by wireless sensor network. Wireless sensor networks make patients' life more comfortable and provide viable solutions. So it is an emerging research topic and it is worth studying. This paper provides study of health WSNs. This paper presents the design\& implementation of healthcare monitoring system using WSN with GSM modem. A test bed is constructed to test the performance of Health Care Monitoring where sensor node measures blood pressure, Electrocardiogram, heart rate, temperature \& Respiration.

\section{ACKNOWLEDGMENT}

With immense pleasure in articulating propounded regards to vulnerable and highly esteemed guide Prof. Labade R. P. and project coordinator Prof. Pawase R. S. who guided with his valuable, experienced and technical knowledge in research and development as well. Special thank to Dr. G. J. Vikhe Patil who always willing to help and give their best suggestions during entire the period of $\mathrm{PG}$ degree and paper writing.

\section{REFERENCES}

[1] O. Chipara, C. Lu, T. C. Bailey, and G.-C. Roman, "Reliable patient monitoring: A clinical study in a step-down hospital unit," Dept. Computer Science Eng., Washington Univ. St. Louis, St. Louis, MO, Tech. Rep. WUCSE-2009-82, Dec. 2009.

[2] T. Gao, C. Pesto, L. Selavo, Y. Chen, J. Ko, J. Lim, A. Terzis, A. Watt, J. Jeng, B. Chen, K. Lorincz, and M. Welsh, BWireless medical sensor networks in emergency response: Implementation and pilot results, [ in IEEE Int. Conf. Technol. Homeland Security, 2008, pp. 187-192.

[3] ISO 9919:2005 Medical Electrical Equipment-Particular Requirements for the Basic Safety and Essential Performance of Pulse Oximeter Equipment for Medical Use, Publication of the ASTM F29.11.05 and ISO TC 121 SC3 working group on pulse oximeters, Mar. 2005

[4] J. Ko, J. Lim, Y. Chen, R. Musaloiu-E., A. Terzis, G. Masson, T. Gao, W. Destler, L. Selavo, and R. Dutton, BMEDiSN: Medical emergency detection in sensor networks, ACM Trans. Embedded Comput. Syst., vol. 10, no. 1, pp. 11:1-11:29, 2010, article 11 .
[5] S. Kumar, "Autosense," NIH GEI project at The University of Memphis, 2007. [Online].

[6] D. Malan, T. Fulford-Jones, M. Welsh, and S. Moulton, BCodeBlue: An ad hoc sensor network infrastructure for emergency medical care, [ in Proc. MobiSys/ Workshop Appl. Mobile Embedded Syst., Jun. 2004, pp. $12-14$

[7] K. Patrick, "A tool for geospatial analysis of physical activity: Physical activity location measurement system (PALMS),' NIH GEI project at the University of California at San Diego, 2007. [Online].Available:http://www.gei.nih.gov/exposurebiology/program/do cs/KevinPatrick.pdf.

[8] G. Virone, A. Wood, L. Selavo, Q. Cao, L. Fang, T. Doan, Z. He, and J. A. Stankovic, BAn advanced wireless sensor network for health monitoring in Proc. Transdisciplinary Conf. Distrib. Diagnosis Home Healthcare, Apr. 2006, pp. 95-100.

\section{BIOGRAPHIES}

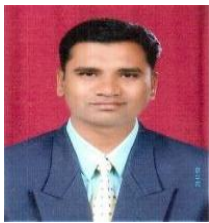

Sunil Rahane has completed BE in Electronics \& Telecommunication from Gangamai College of Engineering, Dhule and now pursuing $\mathrm{ME}$ at AVCOE, Sangamner under Savitribai Phule Pune University. He is working as a Head of Department in Electronics \&Telecommunication in Vamnarao Ithape Polytechnic College, Sangamner.

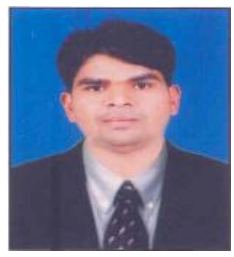

Ramesh Pawase has completed BE in Electronics from Amrutvahini College of Engineering, Sangamner, M.Tech from Dr. Babasaheb Ambedkar Technological University, Lonere and now pursuing $\mathrm{PhD}$ at SITRC Nashik under Savitribai Phule, Pune University. He is working as an Asst Professor in department of Electronics \&Telecommunication in Amrutavhini college of Engineering Sangamner. He is associated with ISTE, IETE, IEEE professional bodies. He had published several research papers in Fiber Optic Communication, Microwave Antenna and now he is working in ASIC based solution for the MEMS sensors using CMOS VLSI Design. 